\title{
1 Versatile Cell-Based Assay for Measuring Base Excision Repair of DNA Alkylation 2 Damage
}

4 Yong $\mathrm{Li}^{1}$, Peng $\mathrm{Mao}^{2,6}$, Evelina Y. Basenko, ${ }^{5,7}$, Zachary Lewis ${ }^{3,4,5}$, Michael Smerdon², Wioletta 5 Czaja ${ }^{* 1,2,8}$

6

$7 \quad{ }^{1}$ The Hormel Institute, University of Minnesota, Austin, Minnesota, 55912, USA. (current

8 address)

$9{ }^{2}$ School of Molecular Biosciences, Washington State University, Pullman, Washington 99164, 10 USA.

$11{ }^{3}$ Department of Microbiology, University of Georgia, Athens, Georgia, 30602, USA.

$12{ }^{4}$ Department of Plant Biology, University of Georgia, Athens, GA, 30602, USA.

${ }^{5}$ Department of Genetics, University of Georgia, Athens, GA, 30602, USA.

${ }^{6}$ Comprehensive Cancer Center, University of New Mexico, Albuquerque, NM, 87131, USA. (current address)

${ }^{7}$ Department of Biochemistry and Systems Biology, University of Liverpool, Liverpool L69 3BX, United Kingdom. (current address)

${ }^{8}$ Department of Biochemistry and Molecular Biology, University of Georgia, Athens, Georgia, 23 30602, USA.

27 *Address for correspondence

28 Wioletta Czaja

29 The Hormel Institute

30 University of Minnesota

31 Austin, Minnesota, 55912, USA

32 Email: wczaja@umn.edu 


\section{Abstract}

DNA alkylation damage induced by environmental carcinogens, chemotherapy drugs, or endogenous metabolites plays a central role in mutagenesis, carcinogenesis, and cancer therapy. Base excision repair (BER) is a conserved, front line DNA repair pathway that removes alkylation damage from DNA. The capacity of BER to repair DNA alkylation varies markedly between different cell types and tissues, which correlates with cancer risk and cellular responses to alkylation chemotherapy. The ability to measure cellular rates of alkylation

42 damage repair by the BER pathway is critically important for better understanding of the

43 fundamental processes involved in carcinogenesis, and also to advance development of new

44 therapeutic strategies. Methods for assessing the rates of alkylation damage and repair, 45 especially in human cells, are limited, prone to significant variability due to the unstable nature of some of the alkyl adducts, and often rely on indirect measurements of BER activity. Here, we report a highly reproducible and quantitative, cell-based assay, named alk-BER (alkylation Base Excision Repair) for measuring rates of BER following alkylation DNA damage. The alk-BER assay involves specific detection of methyl DNA adducts (7-methyl guanine and 3-methyl adenine) directly in genomic DNA. The assay has been developed and adapted to measure the activity of BER in fungal model systems and human cell lines. Considering the specificity and conserved nature of BER enzymes, the assay can be adapted to virtually any type of cultured cells. Alk-BER offers a cost efficient and reliable method that can effectively complement

54 existing approaches to advance integrative research on mechanisms of alkylation DNA damage 55 and repair.

63 Key words: Alkylated DNA damage, alkylating agents, DNA methylation, base excision repair, 


\section{Introduction}

DNA alkylation induced by methylating agents such as environmental carcinogens (e.g., smoke), by-products of cellular metabolism (e.g., methyl group donor S-adenosyl methionine), or chemotherapy drugs (e.g., temozolomide, procarbazine) represents one of the most abundant types of DNA base damage that forms in human cells. Monofunctional alkylating agents, like methyl methanesulfonate (MMS) or the anticancer drug temozolomide (TMZ) induce formation of N-methyl and O-methyl DNA adducts such as N7-methylguanine (7meG), N3methyladenine (3meA) and O6-methylguanine (O6meG) [1, 2]. Methyl DNA adducts (MDAs) have cytotoxic and mutagenic properties because of their ability to block gene transcription and interfere with the fidelity of DNA replication. Persistent and inefficiently repaired methyl DNA adducts can induce microsatellite instability, frameshift mutations, and $G \rightarrow A$ transition mutations, that are commonly found in genes critical for malignant transformation, including the H-ras oncogene or TP53 tumor suppressor gene [3-5]. Despite their carcinogenic properties, DNA alkylating agents, such as dacarbazine, temozolomide and streptozotin, have been used for decades in treating various cancers, including melanoma, glioma, and lymphoma [2, 6, 7]. Therapy with alkylating agents can be effective; however, these agents are extremely toxic and prolonged treatment often leads to chemoresistance and formation of secondary cancers [8, 9]. Human responses to alkylating agents vary considerably between individuals, which highlights the involvement of genetic and epigenetic mechanisms in the modulation of cellular toxicity to alkylating agents $[2,10,11]$.

Base excision repair (BER) is the primary pathway involved in the removal of alkylation DNA damage induced by methylating agents $[2,12,13]$. Repair of methyl DNA adducts through the BER pathway is accomplished in four sequential steps, each carried out by a specific group of enzymes [14]. The first step is catalyzed by DNA glycosylases (e.g., AAG), which specifically recognize and bind to a damaged base, and subsequently catalyze cleavage of the glycosidic bond between the damaged base and DNA backbone $[15,16]$. This reaction results in the release of the damaged base from DNA, and the formation of abasic AP (apurinic/apyridiminic) sites. The second step involves incision of the DNA backbone 5' upstream of the AP sites by AP endonucleases (e.g., APE1), which results in the formation of single strand DNA breaks (SSBs) $[17,18]$. In mammalian cells, AP sites and SSBs are recognized by poly ADP-ribose polymerase 1 (PARP1) [19, 20]. Activated PARP1 catalyzes the formation of ADP-ribose chains, which serve as a docking platform that facilitates recruitment and assembly of the multiprotein BER complex (XRCC1-POL $\beta$-LIG3). Breaks in DNA are filled in by DNA polymerases (primarily POL $\beta$ ) using the undamaged complementary DNA strand as a template 
99 [21]. Nicks in the damaged strand are sealed by ligases (e.g., LIG3), which finalizes repair of the damaged DNA strand $[22,23]$.

101

Importantly, methylation-derived repair intermediates such as AP sites and SSBs are highly cytotoxic and mutagenic. Therefore, individual steps in the BER pathway need to be tightly regulated and coordinated to prevent accumulation of those intermediates, cell death, mutagenesis, and carcinogenesis [2, 24]. Genetic studies in yeast, mouse models, and human cells have demonstrated that loss of the tight coordination between individual steps in the BER pathway can trigger genome instability, increased mutagenesis, or cell death [2, 5, 24-27]. Levels and activities of BER proteins vary significantly between cells, tissues, and individuals and correlate with cancer risk and response to alkylation chemotherapy [2, 10, 11, 25, 28-32]. Therefore, measuring and understanding differences in the rate of BER upon alkylation DNA damage could contribute to the development of new approaches in personalized disease prevention and treatment.

The BER pathway is dysregulated in many cancers and is often associated with cancer heterogeneity, metastasis, and chemoresistance. Pharmacological inhibition of BER with PARP inhibitors (e.g., olaparib) has shown enhanced cytotoxicity of various anticancer agents, especially in tumors with defects in homologous recombination [33-37]. Identifying a pre-existing BER imbalance within a tumor may be highly relevant for determining whether therapy involving PARP inhibitors and alkylating agents can be beneficial.

Quantitation of DNA adduct formation and repair has greatly advanced our understanding of DNA repair processes. A number of methods have been developed for quantitative analysis of various enzymatic steps and the overall capacity of BER to repair alkylation DNA damage. The most sensitive methods for detection and quantitation of alkyl DNA adducts include HPLC/ ${ }^{32} \mathrm{P}$ postlabeling, mass spectrometry-based adductomics, and radiolabeling [38-41]. These methods offer high sensitivity; however, they require specialized equipment, expertise, and complex sample preparation, which hinders the convenient use of those approaches to investigate cellular BER mechanisms.

The most commonly used cell-based methods to investigate BER, include comet assays and host cell reactivation (HCR) assays. The comet assay is a single-cell electrophoresis 128 technique that can be used to assess the capacity of BER to repair alkylation DNA damage 129 when performed under alkaline conditions [42]. This assay can be used to analyze total levels of 130 BER repair intermediates, such as alkali labile sites (e.g., abasic sites) and single strand breaks; 131 however, it does not quantitatively distinguish between these intermediates. The standard 132 comet assay may not reliably detect persistent and intact base modifications (e.g., 7meG or 
3meA) that are not converted to AP sites or SSBs. In addition, the comet assay may not detect lesions that form and persist within highly inaccessible heterochromatin fractions of the genome. Furthermore, the standard comet assay workflow is laborious and prone to day-to-day variability. It may also require extensive optimization of experimental conditions, including $\mathrm{pH}$ or salts used during the alkaline electrophoresis steps, to achieve sensitivity and consistent reproducibility $[42,43]$. HCR is another method that has been used to measure the capacity of BER to repair alkylation DNA damage in living cells $[44,45]$. HCR relies on the transfection of the non-replicating DNA plasmid with a reporter gene (e.g., luciferase) that contains chemicallyinduced DNA base damage, which is subject to repair by the BER pathway. The presence of the DNA base damage within the reporter gene inhibits its expression, whereas the repair of base damage re-activates reporter expression. The HCR assay can be especially challenging to assess repair of alkylation DNA damage, due to in vitro instability of the alkyl DNA adducts (e.g., $7 \mathrm{meG}$ and 3meA), which can markedly affect assay reproducibility [45]. Also, HCR involves a non-genomic DNA substrate that does not necessarily reflect the complexity of the genomic chromatin environment.

More recently, high resolution, high throughput approaches such as LAF-seq (LesionAdjoining Fragment Sequencing) or NMP-seq (N-methyl purine sequencing) utilizing next generation DNA sequencing have been developed to enable precise mapping and quantitation of methyl DNA adducts across the genome, and at specific genomic loci [46, 47]. These approaches offer unprecedented single base resolution, but can be laborious, involving generation of DNA sequencing libraries and extensive bioinformatics analyses of the sequencing data, especially when used with human cells. In addition, those methods may require high (non-physiological) doses of DNA damaging agents and large amounts of input DNA.

Here we report a reliable, gel-based method, called alk-BER, that offers a fast and quantitative measure of BER capacity in living cells. Alk-BER was developed by an adaptation of a previous method for DNA damage quantitation by alkaline gel electrophoresis, originally developed by Sutherland et al. [48]. Alk-BER can be used to assess overall capacity of BER to repair MMS-induced alkylation DNA damage within the genome of living cells. The assay can be

162 used to facilitate identification of new, conserved regulators of the BER pathway by using 163 complementary model eukaryotic systems, including fungal model organisms and human cells.

164 Application of the alk-BER assay could also facilitate identification of BER-deficient cancer sub165 types, which might represent suitable targets for therapy with alkylating agents and/or PARP 166 inhibitors. 


\section{Materials and Methods}

2.1. DNA damage and time course of repair in yeast cells. Yeast (S. cerevisiae) liquid cell cultures were inoculated from single colonies and grown in $10 \mathrm{ml}$ of YPD (Yeast extract -

171 Peptone-Dextrose) medium for $\sim 16 \mathrm{~h}$ at $30^{\circ} \mathrm{C}$ in an orbital shaker. The following day, cells were 172 sub-cultured in fresh media and grown until the cultures reached the logarithmic stage of 173 growth, as determined by measuring the optical density of the cell culture (e.g., $\left.\mathrm{OD}_{600} \sim 0.6\right)$.

174 Next, MMS was added to the liquid cultures at a final concentration of $20 \mathrm{mM}$ and cells were 175 incubated for $10 \mathrm{~min}$ at $30^{\circ} \mathrm{C}$ in an orbital shaker. Alternatively, cells were treated with $3.5 \mathrm{mM}$ 176 MMS for 1- $3 \mathrm{~h}$, followed by removal of media containing MMS and repair time course in fresh 177 media for 1-6 h. Cells were then harvested by centrifugation, and the supernatant fractions 178 containing MMS were removed and disposed following DEHS guidelines. Cell pellets were 179 washed with ice-cold phosphate buffered saline (1X PBS), re-suspended in a pre-warmed YPD 180 media, and allowed to repair for a total of $3 \mathrm{~h}$. Extended repair time points (longer than 4-5 181 hours) were avoided to ensure that restoration of the genome integrity was due to the activity of 182 BER, and not due to lesion bypass and DNA replication. Cultures were incubated with continuous shaking and cell aliquots were collected at different repair time points $[49,50]$.

2.2. Yeast genomic DNA isolation. Yeast genomic DNA was extracted with the glass bead method following previously established protocols [51]. Briefly, cell pellets were mixed with 250 $\mu \mathrm{L}$ of DNA lysis buffer [2\% (vol/vol) Triton X-100, 1\% SDS, $100 \mathrm{mM} \mathrm{NaCl}, 10 \mathrm{mM}$ Tris. $\mathrm{HCl}, \mathrm{pH}$ 8.0, $1 \mathrm{mM}$ EDTA, $250 \mu \mathrm{L}$ of PCl (phenol: chloroform: isoamyl alcohol $=25: 24: 1$ ), and $150 \mu \mathrm{L}$ of acid-washed glass beads, and vortexed vigorously for 4 min. Next, $200 \mu \mathrm{L}$ of 1xTE buffer (10 $\mathrm{mM}$ Tris $\cdot \mathrm{HCl}, \mathrm{pH}$ 7.5, $1 \mathrm{mM}$ EDTA) were added and cell lysates were centrifuged at 14,000 rpm at $4^{\circ} \mathrm{C}$. The supernatant fraction was transferred to a fresh Eppendorf tube and mixed with $1 \mathrm{~mL}$ of ice-cold 200 proof ethanol. Samples were incubated at $-80^{\circ} \mathrm{C}$ for 15 min to facilitate formation of the DNA precipitate. Next, samples were centrifuged at $14,000 \mathrm{rpm}$ at $4^{\circ} \mathrm{C}$, and washed with $70 \%$ ( $\mathrm{vol} / \mathrm{vol})$ ethanol. The DNA pellets were dissolved in $200 \mu \mathrm{L}$ of 1 XTE buffer and incubated with $2 \mu \mathrm{L}$ of RNase A (Thermo Fisher Scientific, cat \# EN0531) at $37^{\circ} \mathrm{C}$ for $1 \mathrm{~h}$ to remove RNA. DNA was subsequently ethanol-precipitated, dissolved in sterile deionized $\mathrm{H}_{2} \mathrm{O}$, and then stored 197 at $-80^{\circ} \mathrm{C}$.

2.3. AAG and APE1 reactions. Purified genomic DNA was processed with (+) or without (-) an 200 enzymatic cocktail composed of AAG (New England BioLabs, cat\# M0313S) and APE1 (New 
201 England BioLabs, cat\# M0282), to convert MMS-induced 7meG and 3meA to SSBs. DNA 202 samples (0.6-1 $\mathrm{gg}$ ) were incubated with $1 \mu \mathrm{L}$ of $A A G$ and $1 \mu \mathrm{L}$ of APE1 in the reaction buffer (70 $203 \mathrm{mM}$ MOPS, pH 7.5,1 mM dithiothreitol (DTT), $1 \mathrm{mM}$ EDTA, 5\% glycerol) at $37^{\circ} \mathrm{C}$ for $1 \mathrm{~h}$ in a 204 total reaction volume of $20 \mu \mathrm{L}$ [52]. Methylated bases were cleaved by AAG glycosylase and the 205 resulting abasic sites were cleaved by APE1 endonuclease. The reactions were stopped by 206 adding DNA loading buffer (50 mM NaOH, 1 mM EDTA, 3\% Ficoll, 0.025\% Bromocresol green, 207 0.041\% Xylene cyanol). Following enzymatic digestion of DNA cleavage products, single and 208 double strand breaks were resolved on 1.2\% alkaline agarose gels and stained with SYBR Gold $209[49,50]$.

2.4. Alkaline agarose gel electrophoresis. Alkaline agarose gel electrophoresis was performed following previously published protocols with modifications [48, 53]. The large gel electrophoresis box and casting tray were used. The agarose solution was prepared by adding $4.3 \mathrm{~g}$ of agarose to $360 \mathrm{ml}$ of $\mathrm{H}_{2} \mathrm{O}$ in a $1 \mathrm{~L}$ Erlenmeyer flask and then heating in a microwave oven until the agarose was dissolved. The solution was cooled to $55^{\circ} \mathrm{C}$ and then followed by addition of a 0.1 volume $(40 \mathrm{ml})$ of $10 \mathrm{X}$ alkaline agarose gel electrophoresis buffer $(500 \mathrm{mM}$ $\mathrm{NaOH}, 10 \mathrm{mM}$ EDTA, pH 8.0). Addition of 10x alkaline buffer to a hot agarose solution should be avoided because $\mathrm{NaOH}$ in the buffer may cause hydrolysis of the agar. The agarose solution was poured into a large gel casting tray. After the gel was completely solidified, it was mounted in the electrophoresis tank. Then the tank was filled with $1 \mathrm{X}$ alkaline electrophoresis buffer until the gel was covered with the buffer at a depth of $3-5 \mathrm{~mm}$ above the gel. DNA samples after AAG and APE1 digestion were collected and 6X alkaline gel-loading buffer (300 mM NaOH, 6 mM EDTA, 18\% Ficoll, 0.15\% Bromocresol green, 0.25\% Xylene cyanol) was added to each sample. Chelating all $\mathrm{Mg}^{2+}$ with EDTA (component of the $6 \mathrm{X}$ alkaline gel-loading buffer) is important before loading the samples onto the alkaline agarose gel because in solutions with a high $\mathrm{pH}, \mathrm{Mg}^{2+}$ can form insoluble $\mathrm{Mg}(\mathrm{OH})_{2}$ precipitates that entrap DNA and inhibit DNA mobility through the gel. Samples were loaded and the gel was run at room temperature at $30 \mathrm{~V}$ for 19-24 h. Alternatively, the electrophoresis can be run at $4^{\circ} \mathrm{C}$ in a cold room. We found that running the gel in a cold room helped improve the sharpness of the DNA bands. Note that after the run is completed, the Bromocresol green dye may not be visible because of dye diffusion in 231 the gel. The gel was transferred to a large plexiglass tray, covered with neutralizing solution (1 $232 \mathrm{M}$ Tris- $\mathrm{HCl}, 1.5 \mathrm{M} \mathrm{NaCl}$ ), and incubated for $30 \mathrm{~min}$ with gentle shaking on an orbital shaker. Next 233 the gel was transferred to staining solution (1X TAE buffer with SYBR gold) and stained for $1 \mathrm{~h}$ 234 with gentle shaking. The container with the gel was covered with aluminum foil to protect the 
staining solution from light. Following staining, the gel was rinsed and de-stained with $\mathrm{H}_{2} \mathrm{O}$ for 30 min with gentle shaking. An image of the gel was acquired using the Storm phosphor imager.

\subsection{Quantitative analysis of DNA damage and repair following MMS treatment.} Quantitation of methylated bases in genomic DNA was performed on phosphor image data by using ImageQuant software (Molecular Dynamics) and number-average DNA length analysis. The number-average length of genomic DNA ( \pm AAG/APE treatment) was used to calculate the average number of SSBs/kb, and the percentage of MDAs removed (\% repair) was determined as described previously $[49,51]$. Briefly, using the ImageQuant software functions, each data point on the gel image is marked with a box encompassing the entire length of the lane to give the total area of each lane. The data point corresponding to $1 / 2$ the total area, designated as $X_{\text {med, }}$ is then determined. The $X_{\text {med }}$ value indicates the median migration distance of the DNA fragments. $X_{\text {med }}$ is converted to the median length $L_{\text {med }}$ of DNA molecules by using a standard curve generated from the migration of DNA-size markers. The number average molecular length, $L_{n}$, is calculated from $L_{\text {med }}$ by using the equation $L_{n}=0.6 L_{\text {med }}$ [54], assuming a Poisson distribution of DNA fragments. Numbers of SSBs/kb is calculated using the following equation; $\mathrm{SSBs} / \mathrm{kb}=1 / \mathrm{L}_{n}(+\mathrm{AAG}+\mathrm{APE} 1)-1 / \mathrm{L}_{n}(-\mathrm{AAG}-\mathrm{APE} 1)$. Calculated numbers of SSBs per $\mathrm{kb}$ DNA fragment indicate numbers of MDAs.

\subsection{DNA damage and time course of repair in multicellular fungus Neurospora crassa.} Buchnner funnel, and washed with $500 \mathrm{ml}$ of VMM media to remove MMS. Washed cells were transferred to pre-warmed VMM media and then allowed to grow at $30^{\circ} \mathrm{C}$ for $4 \mathrm{~h}$ to enable repair of damaged DNA. Aliquots of cells were harvested and immediately frozen in liquid nitrogen. Genomic DNA was isolated and $300 \mathrm{ng}$ of genomic DNA was digested with APE1 endonuclease (cat \# M0282S, New England Biolabs), AAG glycosylase (cat \# M0313S, New England Biolabs), or both enzymes in MOPS reaction buffer (70 mM MOPS, pH 7.5,1 mM dithiothreitol DTT, $1 \mathrm{mM}$ EDTA, $5 \%$ glycerol) for $1 \mathrm{~h}$ and $15 \mathrm{~min}$ at $37^{\circ} \mathrm{C}$. Reactions were stopped by adding alkaline DNA loading buffer (50 mM NaOH, 1 mM EDTA, 3\% Ficoll). Samples were resolved on a 1.2\% alkaline agarose gel. Agarose gels were run in a cold room at $25 \mathrm{~V}$ for $17 \mathrm{~h}$ and then incubated 
SYBR Gold (cat \# S-11494, Life Technologies) for $40 \mathrm{~min}$ and de-stained for 30 min before imaging [55].

2.7. DNA damage and time course of repair in human cells. Human adrenal carcinoma cells (SW13) were cultured in DMEM (Sigma, cat\# D5796) supplemented with $10 \%$ fetal bovine serum FBS (Gibco, cat\# 26140-079). Human fibroblast CHON-002, leukemia HAP1, and lymphoblastoid cells GM12878 were cultured according the ATCC guidelines. Cell cultures were

275 routinely tested for mycoplasma by using a mycoplasma detection kit (ATCC, cat\# 30-1012K).

276 Cell doubling time was determined following ATCC guidelines and viability was routinely 277 monitored with trypan blue. Cells were seeded in T25 flasks ( $-500,000$ cells per dish) and 278 grown for 16-24 h until cells reached 60-70\% confluence. One T25 flask was set for each data 279 point to be collected. In DNA damage dose response experiments SW13 cells were treated with 280 (0- 20mM) MMS in 1xPBS for $10 \mathrm{~min}$ at RT. In DNA damage and repair experiments, SW13 cells were treated with $10 \mathrm{mM}(0.1 \%)$ MMS for $10 \mathrm{~min}$ in 1 XPBS at RT, or alternatively ice-cold, serum-free media can be also used for MMS treatments. Ice-cold treatment is used to inhibit endogenous background BER during the MMS treatment. MMS was removed and cells were washed with 1XPBS. Next, fresh pre-warmed media were added and cells were allowed to repair for 0, 3, 8, or 22 hours. GM 12878 cells were treated with $5 \mathrm{mM}(0.05 \%)$ MMS for 5 min. (K 182001, Thermo Fisher Scientific). DNA was processed with AAG and APE1 enzymes as described above. DNA was resolved on a 1.2\% alkaline agarose gel, run at $30 \mathrm{~V}$ for $22 \mathrm{~h}$, stained with SYBR gold, and quantified as described above.

\subsection{Western Blotting}

$292 \mathrm{HAP} 1, \mathrm{SW} 13$ and $\mathrm{CHON}-002$ cells were harvested and frozen at $-80^{\circ} \mathrm{C}$. Protein extracts were 293 prepared in a RIPA buffer (Santa Cruz, sc-24948) plus phosphatase inhibitor (Santa Cruz, sc29445044 and Sc-45044) and equal amounts of protein were separated on TGX stain-free (Bio-Rad, 295 cat\#5678083). Proteins were transferred onto TransBlot LF PVDF (Bio-Rad) and analyzed by 296 Western blotting using antibodies recognizing the following proteins: AAG (Abcam ab155092, 297 42KD, 1:5000), beta-actin (Sigma A5441, 33KD, 1:5000). 


\section{Results}

3.1. Alk-BER assay workflow. The conserved nature of the BER pathway enables easy adaptation of the assay to various cell types and model organisms from lower eukaryotes to human cells. We initially developed the alk-BER assay to measure BER in yeast cells (S. cerevisiae) and successfully adapted the assay to other fungal model organism ( $N$. crassa) and human cells. The alk-BER assay is based on the enzymatic conversion of the MMS-induced damaged DNA bases to single strand breaks (SSBs), which are subsequently resolved on alkaline agarose gels and quantified. The rate of BER can be analyzed by performing a DNA damage and time course for repair and assessing the rate of removal of damaged bases from the total genomic DNA. The assay is performed in 5 simple steps (Fig. 1) and can be completed in 3 days. The first step involves exposing the cells to sub-lethal doses of MMS to induce formation of methyl DNA adducts (mainly $7 \mathrm{meG}$ and 3meA). In the second step, cell aliquots corresponding with DNA damage and repair time points are collected and total genomic DNA is isolated. The third step involves conversion of MDAs to SSBs with BER enzymes (AAG glycosylase and APE1 endonuclease) that specifically bind and cleave the DNA at sites of MDAs. The fourth step involves running the samples on alkaline agarose gels to separate DNA fragments containing SSBs from the bulk genomic DNA that does not contain damage. The final step involves staining of the separated DNA fragments in the gel, acquiring an image of the gel and performing quantitation of MDAs. The alk-BER method directly quantifies the numbers of MDAs in purified genomic DNA and analyzes the kinetics of DNA repair at the whole-genome level. In order to assess the capacity of BER using the alk-BER assay, cells should be exposed to sub-lethal doses of MMS, that induce detectable levels of MDAs, but do not induce substantial cell death. To determine sub-lethal doses for specific cell line it is recommended to perform MMS dose response experiment encompassing range of MMS doses from low to high.

323 Cell death is induced when unrepaired lesions persist due to inability of BER to efficiently repair 324 abnormally high levels of DNA damage or when BER activity is compromised (e.g., BER gene 325 mutants). BER capacity should also be analyzed within a specific, experimentally determined 326 window of time following DNA damage, typically 0-3 $\mathrm{h}$ for yeast cells, or 0-24 $\mathrm{h}$ for human cells, 327 to avoid interference from lesion bypass and DNA replication. 
Figure 1. Schematic outline of alk-BER assay. The assay involves exposing the cells to MMS (step 1), isolation of total genomic DNA (step 2), conversion of MMS-induced methylated bases to SSBs with damage specific enzymes AAG and APE1 (step 3), separation of DNA fragments containing SSBS by alkaline agarose gel electrophoresis (step 4), gel staining, imaging, and quantitation of MDAs (step 5).

3.2. Alk-BER in fungal cells. A DNA damage dose response assay was performed by exposing yeast cells (strain BY4741) to increasing doses of MMS (5, 10, $20 \mathrm{mM}$ ) for $10 \mathrm{~min}$ at $30^{\circ} \mathrm{C}$. Total genomic DNA was isolated and treated with AAG and APE1 enzymes. DNA samples were resolved by alkaline agarose gel electrophoresis and numbers of MDAs were quantified as described above. As the gel is run at alkaline $\mathrm{pH}$, hydrogen bonding between the two DNA strands is broken to facilitate separation of strands containing breaks from nondamaged genomic DNA. The denatured DNA is maintained in a single-stranded state and 361 migrates through the alkaline gel as a function of its size, forming a distinct smear. Increased 362 formation of MMS-induced DNA lesions in response to increased doses of MMS is shown as 
increases in lower molecular weight DNA molecules, also visible as a smear (Fig. 2A). The frequency of MDAs (7meG and 3meA) was calculated and plotted as the number of methyl A, G per kb fragment as a function of increasing doses of MMS (Fig. 2B). The proportional relationship between increasing MMS doses and numbers of MDAs indicates a high sensitivity of the alk-BER method, $\sim 1.0$ MDAs per 10,000 bases, that is induced by 5mM MMS dose, and -4.0 MDAs per 10,000 bases induced by 20mM MMS in yeast cells (Fig. 2B).

DNA damage and time course of repair has been performed to evaluate the overall rate of BER to repair alkylation DNA damage in the yeast wild type strain BY4741. DNA molecules containing MMS-induced MDAs are converted to SSBs. Proficient DNA repair and restoration of genome integrity can be visually monitored as progressive shortening of the DNA smear in migration and restoration of the genome integrity by formation of high molecular weight DNA. DNA was processed with AAG and APE1 and resolved on alkaline agarose gels as described previously. A representative gel image demonstrating DNA damage and repair in the BY4741 yeast strain is shown (Fig. 2C) and corresponding quantitative analysis of the gel is also shown (Fig. 2D). BER in the WT BY4741 yeast strain is proficient, and over $80 \%$ of the total MDAs in the genome are repaired after $3 \mathrm{~h}$ repair time at the dose used (Fig. 2D). The specificity of the alk-BER method was validated using yeast and Neurospora mutant cells deficient in BER. The yeast mag1 $1 \Delta$ mutant has no Mag1 glycosylase (orthologue of human AAG) and is deficient in cleaving MMS-induced $7 \mathrm{meG}$ and 3meA from the DNA. Cells from the WT and mag $1 \Delta$ strains were exposed to MMS for a total of $3 \mathrm{~h}$ followed by MMS removal and a $6 \mathrm{~h}$-long repair time course to allow cells to repair damaged DNA. During the $3 \mathrm{~h}$-long MMS exposure, mutant cells displayed higher levels of MDA formation as compared to WT because endogenous BER is inactive in the mutant cells, which results in accumulation of MDAs under the conditions of continuous MMS exposure. After removal of MMS, WT cells with proficient BER were able to clear most of the lesions during the repair time course, whereas BER-deficient mag1 $\Delta$ cells contained high levels of unrepaired MDAs (Fig. 3A,B,C). The alk-BER assay was successfully adapted to multicellular fungal model Neurospora crassa. DNA damage and repair time course was performed with Neurospora WT and mag1s cells [55]. Neurospora cells of the wild type laboratory strain were exposed to $3.5 \mathrm{mM}$ MMS continuously for 3 hours, followed by repair time course in media without MMS for 5 hours. Genomic DNA was isolated and processed with combinations of AAG and APE1 enzymes and resolved on alkaline agarose gel. BER capacity to repair MMS-induced lesions in Neurospora cells is very efficient, with nearly complete restoration of genome integrity following $2 \mathrm{~h}$ repair period (Fig.S2). 
A

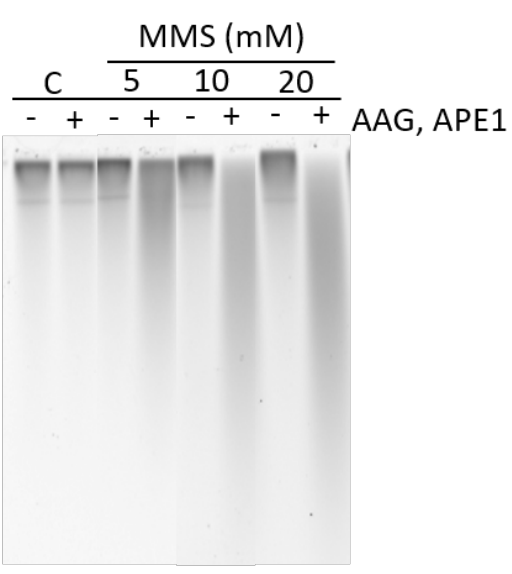

C

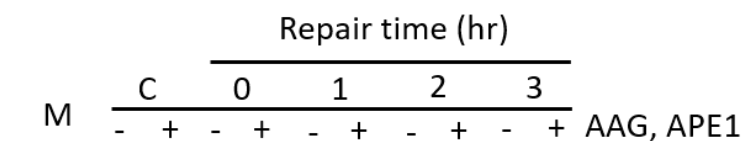

B

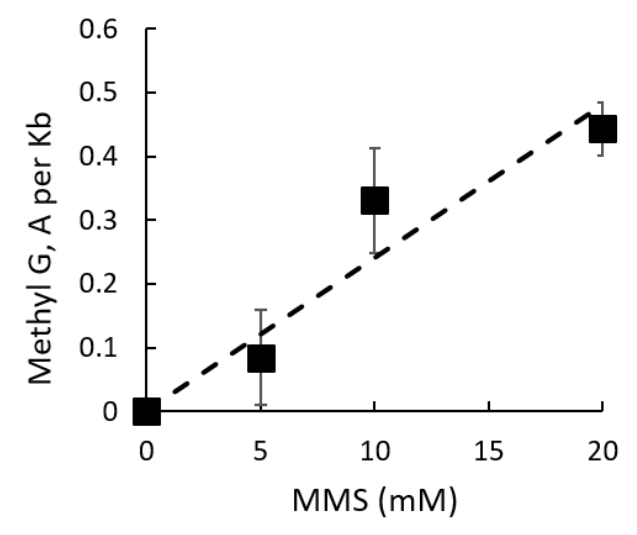

D

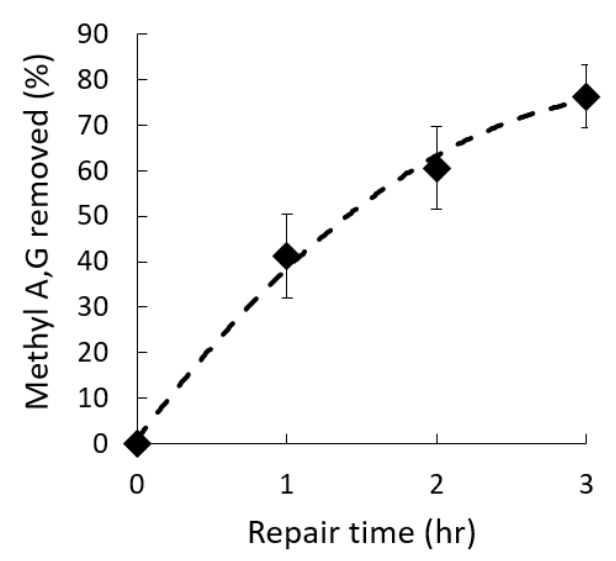

Figure 2. Alk-BER assay in yeast cells (S. cerevisiae). A) Representative alkaline agarose gel image of MMS-induced DNA damage dose response in the BY4741 strain of S. cerevisiae. Genomic DNA of cells not exposed to MMS (C: control), and DNA of cells exposed to increasing doses of MMS $(5,10$, or $20 \mathrm{mM})$ was resolved on alkaline agarose gel. Each DNA sample was treated with $(+)$ and without $(-)$ a cocktail of AAG and APE1 enzymes. B) Dose dependent increase in the numbers of MMS-induced methyl G, A per $1 \mathrm{~kb}$ DNA fragment. Each data point denotes the average value and standard deviation of three independent experiments. C) Representative gel image of DNA damage and repair time course in the BY4741 strain of $S$. cerevisiae. M: DNA size standard lambda/HindIII. C: control, cells not exposed to MMS, 0: cells collected after $10 \mathrm{~min}$ exposure to $20 \mathrm{mM}$ MMS, 1-3 h: cells collected after 1, 2, $3 \mathrm{~h}$ of repair. D) Quantitative representation of data displayed in panel C. Formation and repair of MMS- 
411 deviation. Gel image presented in panel A has been cropped. Uncropped gel image has been 412 included in the supplementary data.

A

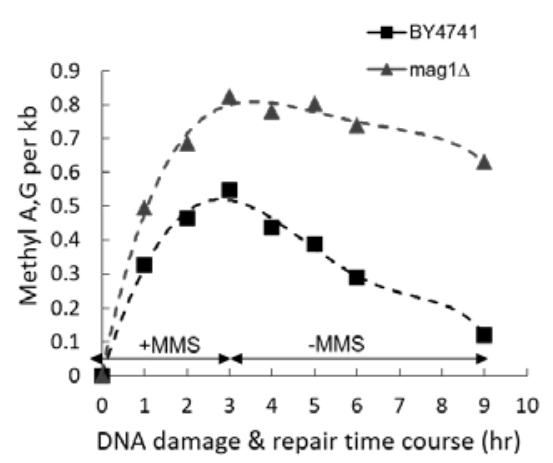

B

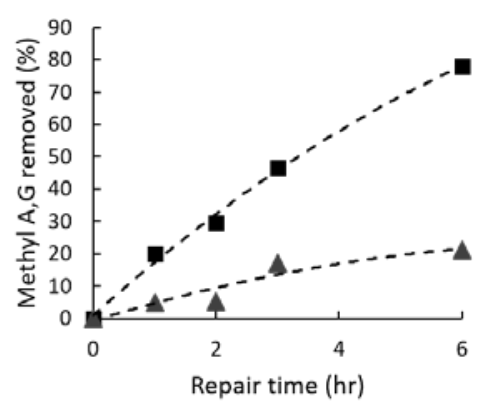

C

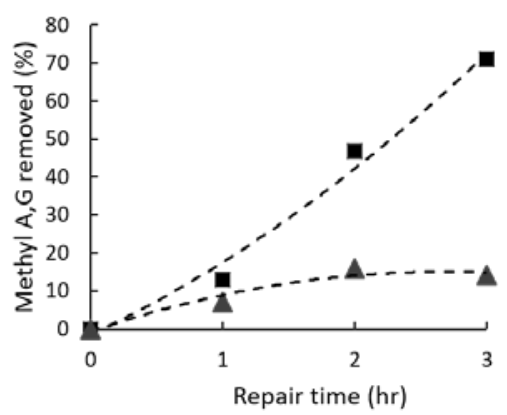

413

414

415

416

417

418

419

420

421

422

423

424

425

426

427

428

429

430

431

432

433

434

435

436

437

Figure 3. Alk-BER assay validation with BER-deficient yeast mutant cells, mag1 $\triangle$. A). The BER rate was analyzed in mag1 $\Delta$ mutant. WT and mutant cells were treated with $3.5 \mathrm{mM}$ MMS for $1-3 \mathrm{~h}$, followed by removal of media containing MMS and repair time course in fresh media for 1-6 h. B). Repair rates expressed as a function of \% of methyl A, G removed over the repair time. C). Cells were treated with $20 \mathrm{mM}$ MMS for $10 \mathrm{~min}$ followed by repair time course for total of 3 hours. Repair rates expressed as a function of \% of methyl A, G removed over the repair time.

3.3. Alk-BER in human cells. The human adrenal carcinoma SW13 cell line was used to adapt and optimize the alk-BER assay for assessing rates of BER in human cells. A series of MMS-dose response experiments were initially performed to determine the appropriate range of MMS concentration and time of the exposure for induction of detectable levels of MDAs at sublethal MMS doses. Cell viability was routinely monitored with trypan blue [56]. Representative MMS dose response data are presented in Fig. 4A,B. Increases in the smear length in response to increasing doses of MMS in the (+AAG\&APE1) lanes indicate enhanced formation of MDAs. The minimal smear in (-AAG\&APE1) lanes reveals formation of MDA-derived BER intermediate AP sites and SSBS that form in DNA as a result of the continuous activity of endogenous BER during MMS exposure. AP sites are fragile in alkaline conditions and can spontaneously convert to SSBs contributing to the smear in (-enzyme) lanes. The proportional relationship between increasing MMS doses and numbers of MDAs indicates a high sensitivity of the alk-BER method, $\sim 0.7$ MDAs per 10,000 bases with 5mM MMS dose in human cells. Efficiency of the individual enzymes, AAG and APE1 to convert MMS-induced MDAs to SSB in genomic DNA was assess. We found that the cocktail of both enzymes AAG and APE1 works 
most efficient in converting MDAs to SSBs (Fig. 4C). The BER capacity in SW13 cells was analyzed by performing DNA damage and a time course of repair as described in the methods section. Cells were exposed to $10 \mathrm{mM}$ MMS for $10 \mathrm{~min}$ in 1XPBS at RT, followed by removal of MMS and repair for $22 \mathrm{~h}$ in fresh media. The MMS dose used was a sublethal dose, that did not

442 trigger significant cell death, as demonstrated by the cell viability data (Fig. 4F). After 22hr post

443 MMS exposure nearly $70 \%$ of the genome was restored in SW13 cells. Representative data 444 showing the image of the alkaline agarose gel and data quantitation are presented (Fig. 4D,E).

445 Other human cell lines were subject to alk-BER assay, including untransformed fibroblast cells $446 \mathrm{CHON}-002$, and leukemia cancer cells HAP1. The BER capacity to remove MMS-induced 447 adducts was quantitated over distinct repair time points. The removal of MDAs appears very 448 slow ( 0-30\% repair) during the first 0-8hr post MMS exposure and is consistently observed in 449 many different human cell lines we tested. Interestingly, the repair rates vary significantly 450 between different cell lines, and unlike in fungal cells, the rates do not appear to correlate well 451 with the levels of AAG enzyme in the panel of cell lines we tested (Fig.5A,B). Additionally, alk452 BER assay was performed with human lymphoblastoid cell line GM12878. Cells were exposed 453 to $5 \mathrm{mM}$ MMS for $5 \mathrm{~min}$, and repair rate was analyzed at 2.5 and $5 \mathrm{~h}$ in the repair time in media 454 without MMS. Clearly, very slow repair was detected during the initial $5 \mathrm{hr}$ repair (Fig. S3). 455 Specificity of alk-BER was analyzed by exposing SW13 cells to increasing doses of oxidative 456 agent hydrogen peroxide (H2O2), and temozolomide (TMZ), clinically used SN1 alkylator, 457 known to induce 7meG, 3meA and O6meG adducts [57]. Exposure to $\mathrm{H} 2 \mathrm{O} 2$ does not result is 458 formation of a dose-dependent DNA smear, indicating that alk-BER assay is specific to methyl 459 adducts, and it cannot detect oxidative DNA damage (Fig. S1A). As expected, alk-BER can 460 specifically detect TMZ-induced DNA methyl adducts in a dose dependent manner (Fig. 461 S1B,C), although the TMZ potency to induced MDAs dose used in our experiment appears less 462 than the potency of MMS. 
A

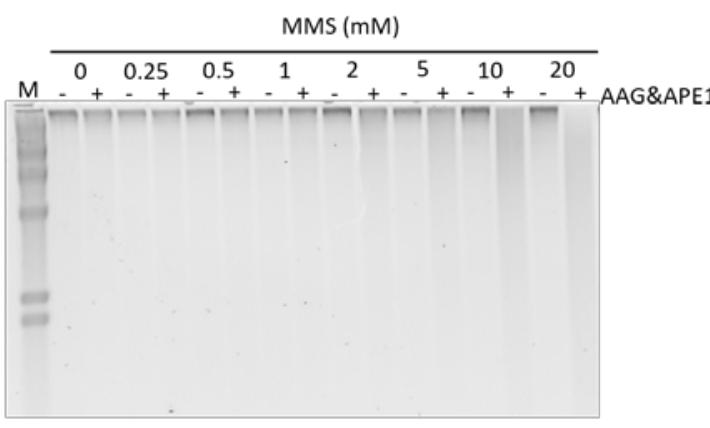

D

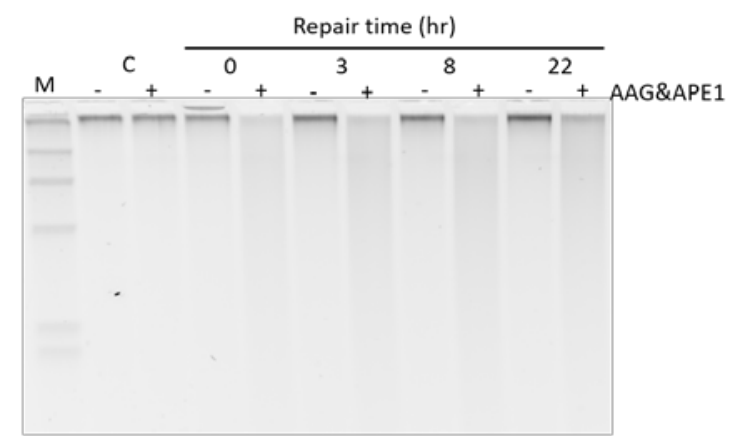

B

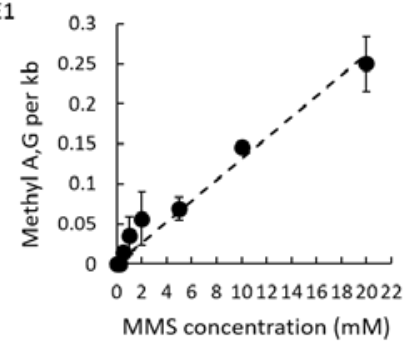

E

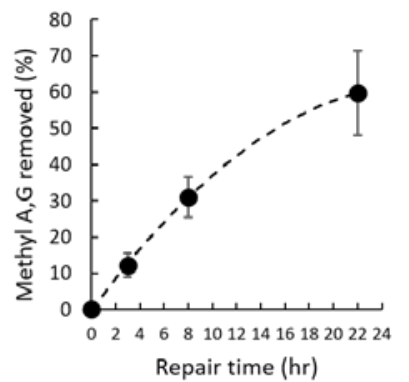

C

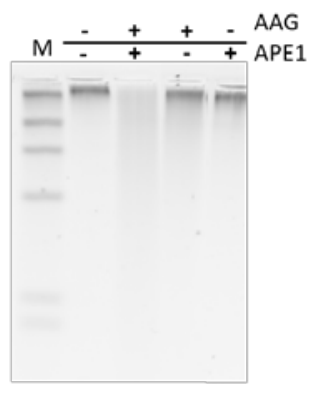

F

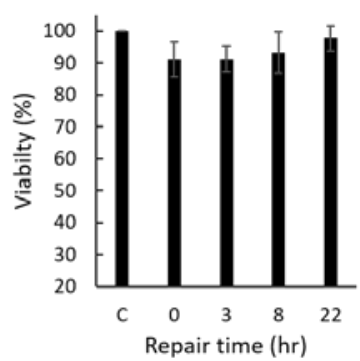

Figure 4. Alk-BER assay in human cells. A) MMS dose response in SW13 cells. Cells were treated with increasing doses of MMS for 10min at RT. Representative alkaline agarose gel image is shown. B) Quantification of methyl A, G per $1 \mathrm{~kb}$ DNA fragment as a function of increasing MMS dose. The graph represents quantification of the data in panel A. C) Efficiency of double enzyme (AAG\&APE1), and single enzymes: (AAG only), and (APE1 only), in converting methyl DNA adducts to SSBs. D) Alkaline gel image representing DNA damage and repair time course. SW13 cells were exposed to 10mM MMS for 10min. Genomic DNA was

471 isolated, and processed with double enzyme AAG\&APE1 digest. E) Quantification of the repair 472 and removal of methyl A,G as a function of time. F) SW13 cell viability measured by trypan blue.

473 Gel image presented in panel $C$ has been cropped. Uncropped gel image has been included in 474 the supplementary data. 
A

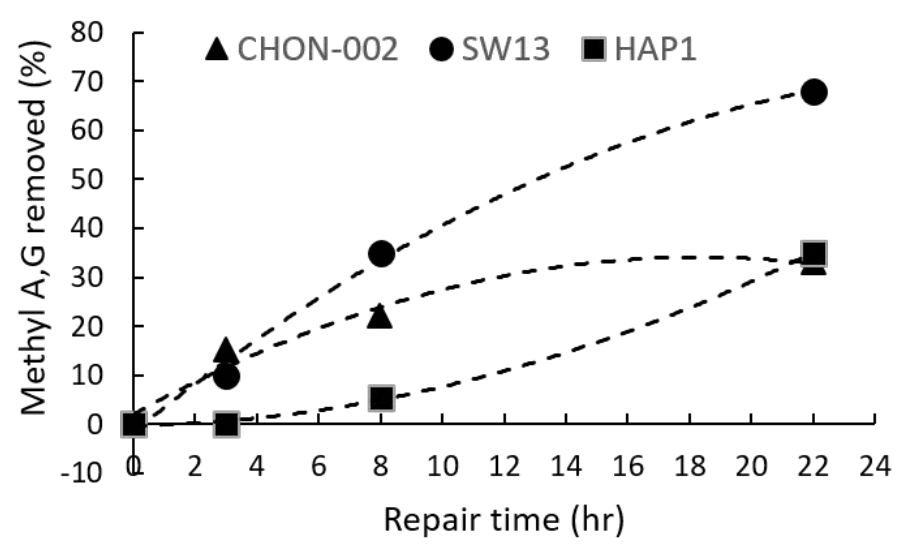

B

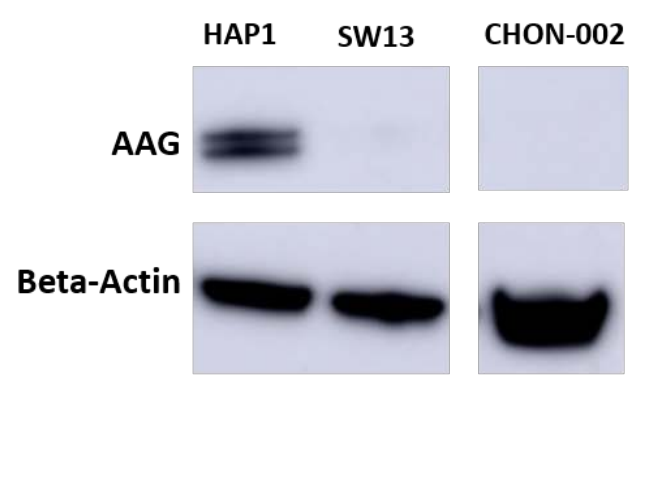

477

478

479

480

481

482

483

484

485

486

487

488

489

490

491

492

493

494

495

496

497

498

499

Figure 5. The repair of MDAs is slow in human cells and does not correlate well with the levels of endogenous AAG enzyme. DNA damage and repair time course experiment was performed in several human cell lines; CHON-002, SW13, and HAP1. Cells (60-70\% confluent) were exposed to $10 \mathrm{mM}(0.1 \%) \mathrm{MMS}$ in $1 \times \mathrm{XPS}$ for $10 \mathrm{~min}$ at RT, followed by DNA repair time course $0,3,8$ and 22 hours at $37^{\circ} \mathrm{C}$. A) DNA repair rates were quantitated individually for each cell line and expressed as a percentage (\%) of the removed methyl A,G, as compared to the $0 \mathrm{hr}$ time point. B) Endogenous levels of AAG enzyme were detected by Western blotting.

\section{Discussion}

The efficiency of BER in repairing alkylation DNA damage varies substantially between different cells, tissues, and individuals, and has important implications in cancer development and treatment $[1,2,58,59]$. BER efficiency is a result of a complex interplay between genetic and epigenetic factors influencing the abundance and activity of the BER enzymes, and the individual steps in the BER pathway. Ability to measure the formation and rates of repair of alkyl DNA adducts in genomic DNA provides a direct assessment of BER efficiency in a given cell type.

Here, we report a quantitative cell-based assay, alk-BER (alkylation Base Exxcision Repair), adapted and optimized for measuring efficiency and rates of BER following alkylation DNA damage in fungal model organisms (S.cerevisiae, N.crassa) and human cell lines (SW13, CHON-002, HAP1 and GM12878). Alk-BER offers a simple, time- and cost-efficient, cell-based method for quantitative analysis of alkylation DNA damage and repair in the genomic DNA. The 
alk-BER assay can be used to determine BER efficiency in various cell types, by assessment of the rates of methyl DNA adducts removal from the DNA over time.

Yeast cells have been extensively used to study DNA repair processes in eukaryotic cells [60]. Yeast have a robust and conserved BER pathway to repair alkylation DNA damage. Using alk-BER assay, we found that in wild type strains of fungal model organisms (S. cerevisiae and $N$. crassa), BER proceeds quite rapidly, following removal of the MMS from the growth media. We showed that BER in the BY4741 strain of S. cerevisiae is nearly completed within 3-4 h post exposure since nearly $80-90 \%$ of the lesions were removed from the genome (Fig. 2C, D). Similarly, repair of alkylation DNA damage has been nearly completed within 2-4 $\mathrm{h}$ in the wild type laboratory strain of $N$. crassa [55] (Fig.S2). We also showed that BER-deficient mag1 yeast mutant cells were deficient to clear MMS-induced lesions and accumulated MDAs over time, which validates specificity of the alk-BER assay (Fig. 3A,B,C). The human genome is much larger therefore repair is expected to take longer compared to lower eukaryotes. We found that the majority of the genome ( $70 \%$ lesions removed) was restored following $22 \mathrm{~h}$ post MMS exposure in SW13 cells (Fig. 4D,E, 5A), which is consistent with previous studies reporting that majority of DNA alkylation repair in mammalian cells can be completed within $24 \mathrm{~h}$ post exposure, as revealed by results generated with various quantification methods [39, 61-65]. We found that the rates of BER to remove MMS-induced DNA adducts vary significantly between SW13 and CHON-002, and HAP1 cell lines and do not correlate well with the endogenous levels of AAG enzyme in these cell lines (Fig. 5A,B). These rates can be influenced by the endogenous levels and activities of various BER enzymes, including additional glycosylases, and other regulators of DNA repair. Future studies are needed to further investigate the mechanisms and regulators of DNA alkylation repair in human cells.

In lower eukaryotes (S.cerevisiae, N.crassa), the rate of repair of MMS-induced methyl DNA adducts is strongly dependent on the functional MAG1 glycosylase, where mag1 $1 \Delta$ mutants

525 demonstrate abolished ability to repair MDAs. Interestingly, repair of MDAs in certain 526 mammalian cells does not appear to be exclusively dependent on AAG glycosylase. It has been 527 reported that the alkylated bases $3 \mathrm{meA}$ and $7 \mathrm{meG}$, both $A A G$ substrates generated from MMS 528 treatment, are removed from the genome of AAG-deficient embryonic stem cells, with slower 529 kinetics for 3meA but comparable kinetics for $7 \mathrm{meG}$ [66]. Other study revealed that similar 530 levels of $7 \mathrm{meG}$ were detected in livers of $\mathrm{AAG}^{+} /^{+}$and $\mathrm{AAG} \%^{-}$mice $24 \mathrm{hr}$ after exposure to MNU 531 [67]. These studies suggest that in mammalian cells methyl DNA adducts can be excised and 532 repaired in the absence of AAG enzyme, perhaps by involvement of other glycosylases, or 
533 spontaneous depurination. Future application of alk-BER could facilitate further understanding

534 of the role of $A A G$ and other factors in regulation of human BER.

535 The alk-BER could serve as useful framework for number of approaches to study repair of 536 DNA alkylation. For example, alk-BER assay could be used to distinguish, in a quantitative way, 537 between the levels of MDAs and levels of downstream repair intermediates, such as AP sites.

538 Highly specific and sensitive detection of AP sites could also be performed by processing of the 539 sample with the AAG enzyme only (converts MDA to AP sites) and subsequent detection of AP 540 sites using a highly sensitive AP site detection kit (e.g., Abcam, ab 211154). Alk-BER assay can 541 also serve as a framework for quantification of gene-specific repair when coupled with Southern 542 blot and hybridization of gene-specific probes. Alk-BER could also be useful in detection and 543 quantification of MMS-induced methyl DNA adducts in preparation and optimization of samples 544 for the approaches involving next generation sequencing, such as NMP-seq.

545 In summary, the alk-BER assay offers a versatile, reliable and affordable approach for 546 quantitative analysis of DNA damage formation and repair following exposure to DNA 547 methylating alkylating agents. The alk-BER assay can be easily optimized to be used in any 548 type of cultured cells, and integrated with the existing approaches to study mechanisms 549 regulating BER balance and capacity. The assay has the ability to detect imbalances in the 550 activity of the BER process, that is highly relevant to cancer development and treatment. 551 Quantitative analyses of DNA alkylation damage and repair using fungal genetic model 552 organisms and human cell lines offer unique opportunities to identify novel, conserved 553 regulators of $B E R$.

555 Acknowledgements

556 We thank Dr. Ann Bode for help with proof reading the manuscript. We would like to 557 acknowledge Dr. John Wyrick for helpful discussions and intellectual contributions to this work. 558 This work was supported by grant R01ES002614 from the National Institute of Environmental 559 Health Sciences (NIEHS) (to M.J.S. and J.J.W.), R21ES028549 from NIEHS to W.C., and 560 Faculty Research Grant from University of Georgia to W.C. The contents are solely the 561 responsibility of the authors and do not necessarily represent the official views of the NIEHS, $562 \mathrm{NIH}$. 
A

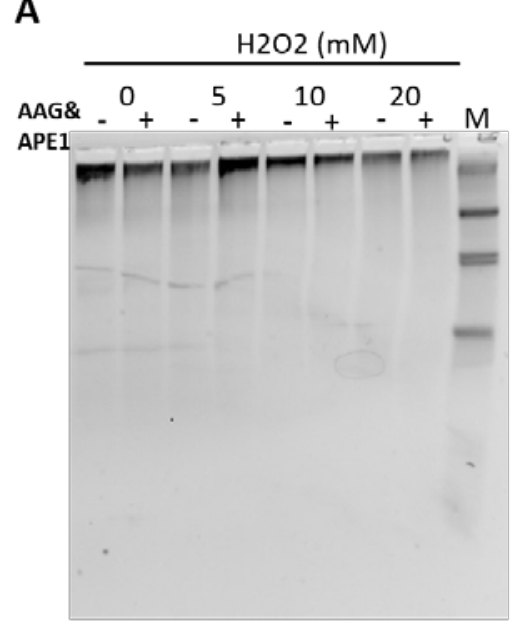

B

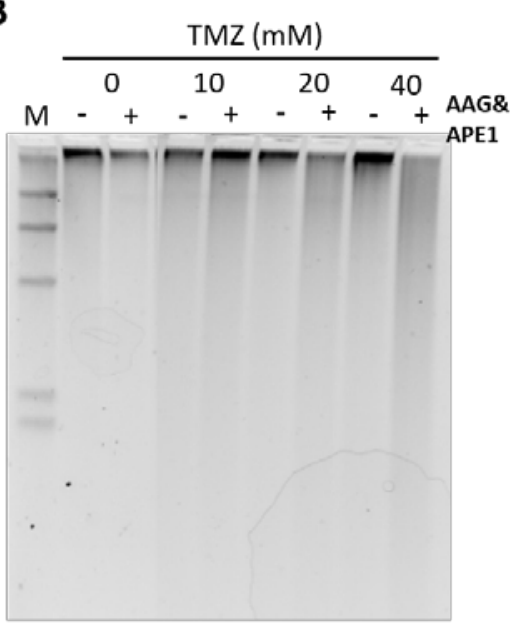

C

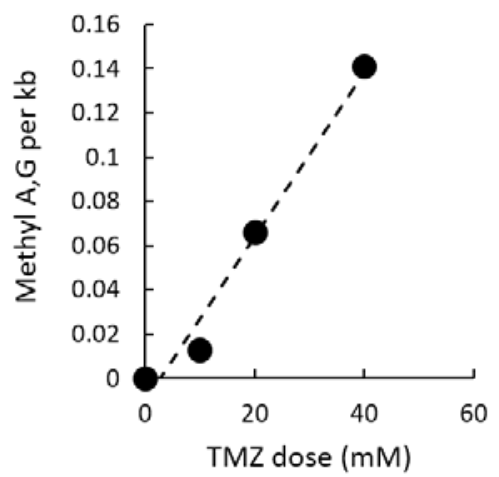

567 Figure S1. Specificity of alk-BER. A) Hydrogen peroxide (H2O2) induced DNA damage. SW13 cells were exposed to increasing doses of $\mathrm{H} 2 \mathrm{O} 2$ for $5 \mathrm{~min}$ at RT, followed by DNA purification, AAG\&APE1 digest and alkaline agarose gel electrophoresis. B) Temozolomide (TMZ) induced DNA damage. SW13 cells were exposed to increasing doses of TMZ for 10 min at RT, followed by DNA purification, AAG\&APE1 digest and alkaline agarose gel electrophoresis and data quantification. C) Quantification data of TMZ dose dependent accumulation of methyl

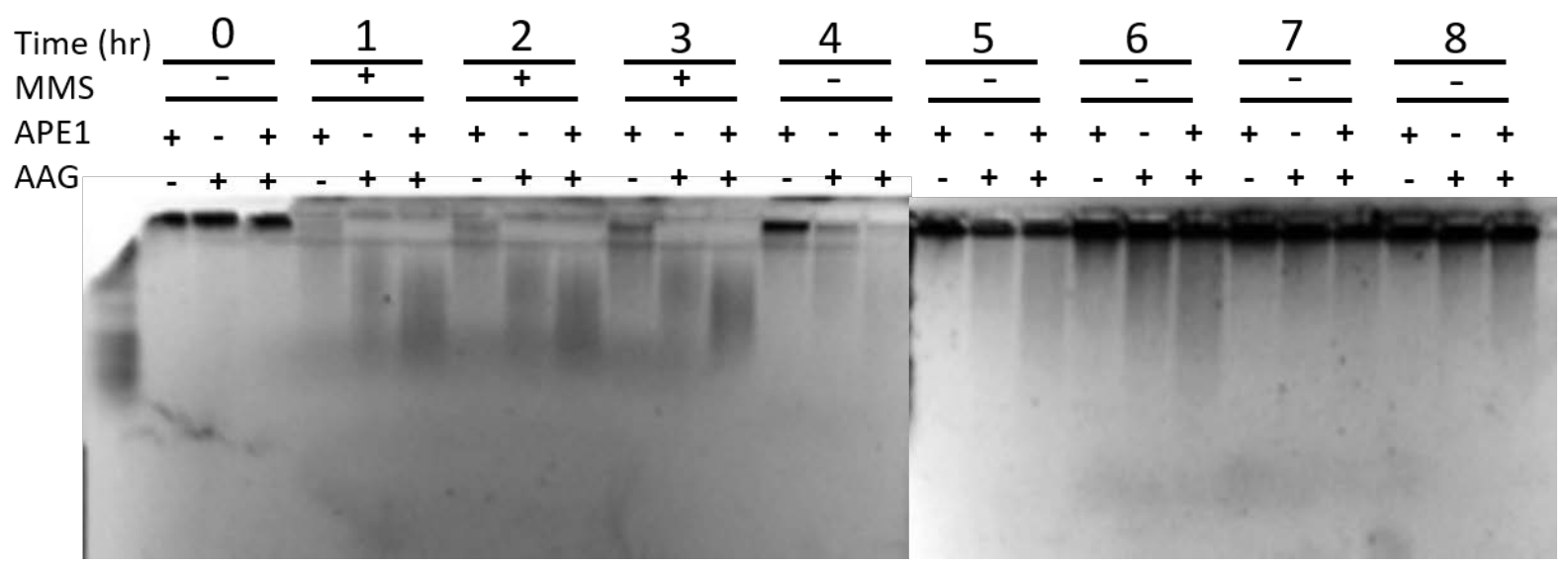

Figure S2. Alk-BER assay in Neurospora crassa. Representative alkaline agarose gel image of MMS-induced DNA damage, followed by DNA repair in the wild type strain of Neurospora, 0: control genomic DNA from cells not exposed to MMS; 1-3 hours: DNA from cells exposed to 3.5mM MMS continuously for 1, 2 and 3 hours respectively; 4-8 hours: DNA from cells that were allowed to repair DNA in media without MMS for 1-4 hours respectively. Each DNA sample was treated with combination of human APE1 and AAG enzymes: APE1 $(+)$ and without AAG (-), without APE1 (-) and with AAG (+), and with both enzymes APE $(+)$ \& AAG $(+)$. 
A

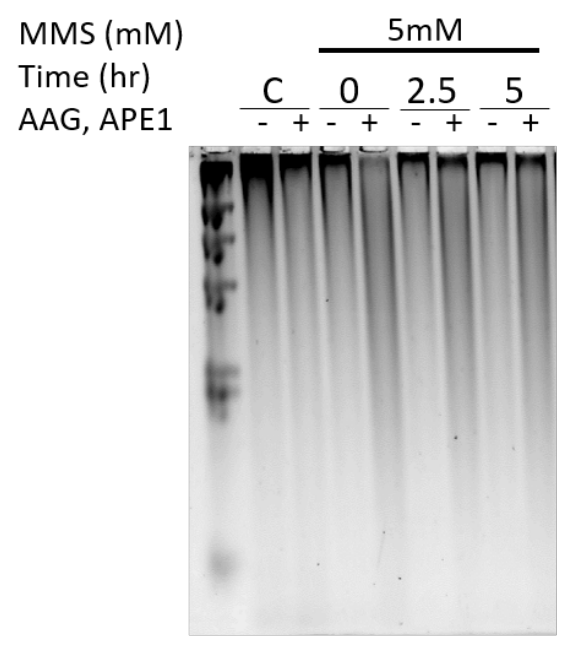

B

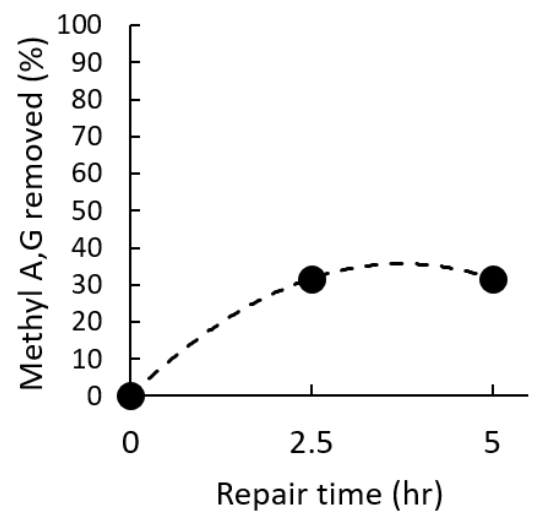

Figure S3. Alk-BER assay in human lymphoblastoid cell line GM12878. The representative alkaline agarose gel illustrates DNA damage and repair time course performed with GM12878 cells. Cells were treated with $5 \mathrm{mM}$ MMS for 5 minutes, MMS was removed and cells were allowed to repair DNA for 2.5 and 5 hours.

\section{Uncropped gel images}

586 Uncropped gel image for Figure 2A.

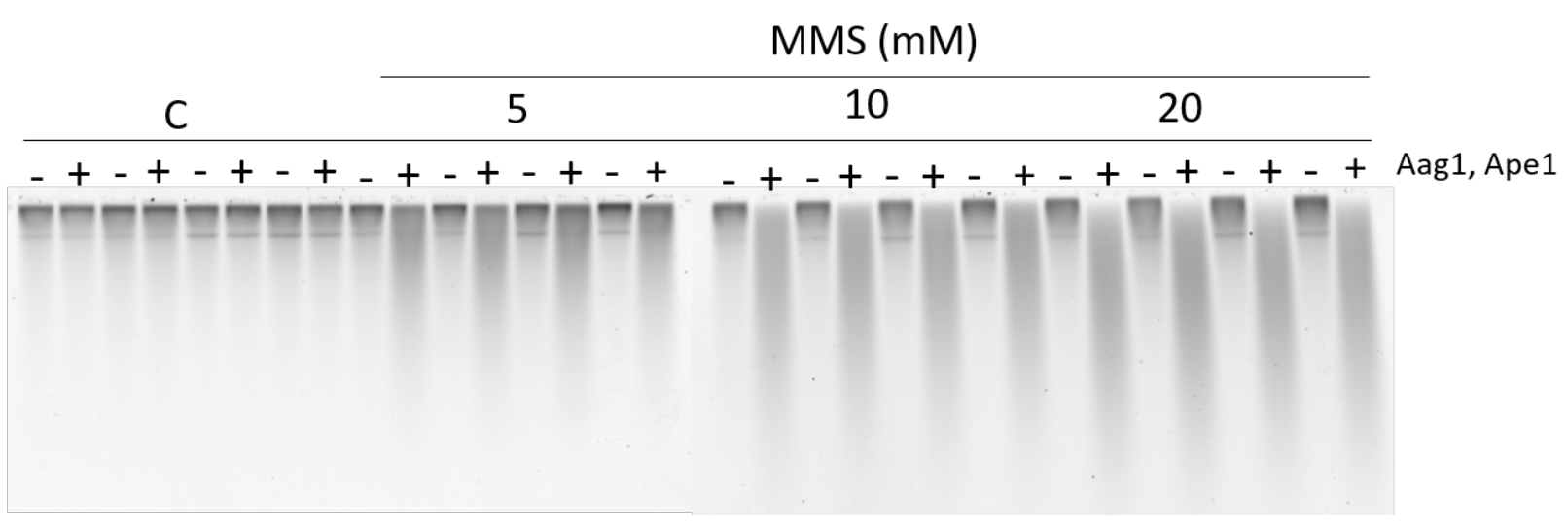


bioRxiv preprint doi: https://doi.org/10.1101/2021.02.25.432902; this version posted April 29, 2021. The copyright holder for this preprint (which was not certified by peer review) is the author/funder. All rights reserved. No reuse allowed without permission.

589 Uncropped gel image Figure 4C.

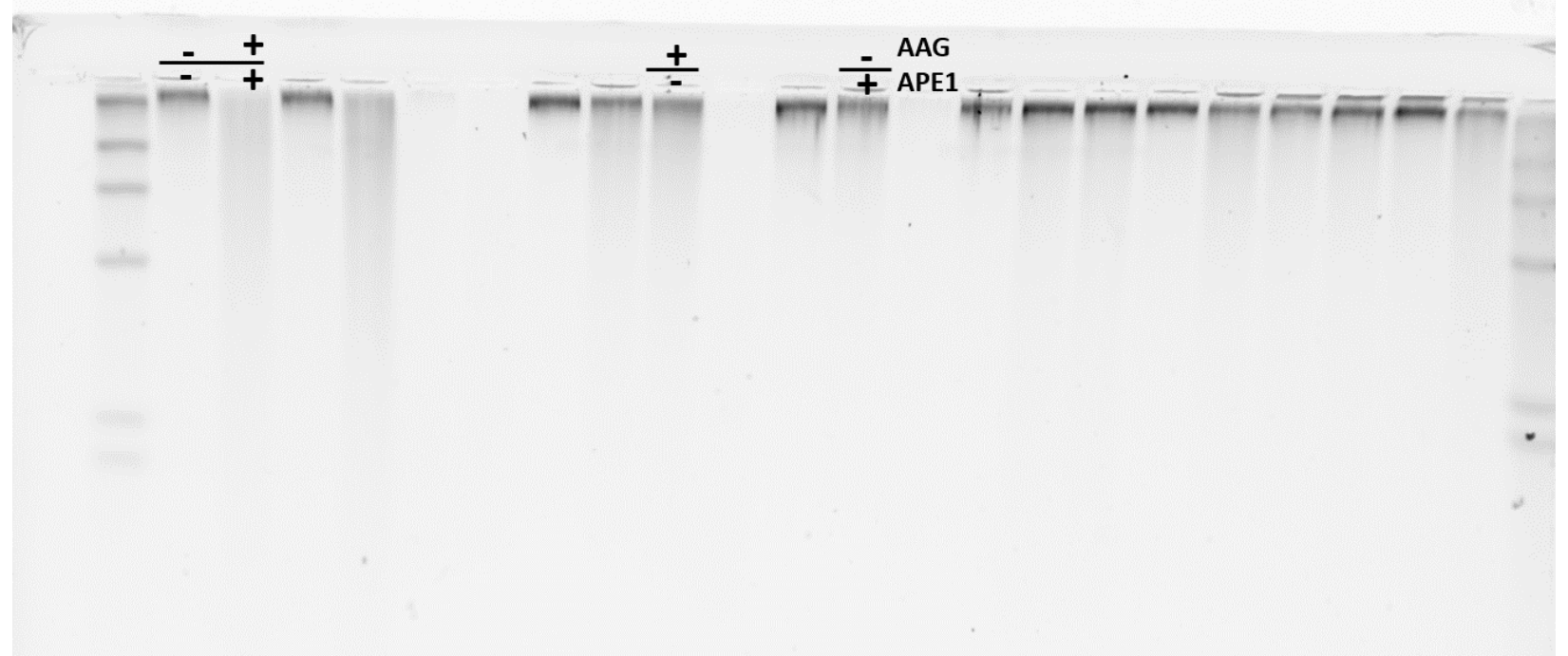

590 
592

593

594

595

596

597

598

599

600

601

602

603

604

605

606

607

608

609

610

611

612

613

614

615

616

617

618

619

620

621

622

623

624

625

626

627

628

629

630

631

632

633

634

635

636

637

638

639

\section{References}

1. Beranek, D.T., Distribution of methyl and ethyl adducts following alkylation with monofunctional alkylating agents. Mutat Res, 1990. 231(1): p. 11-30.

2. Fu, D., J.A. Calvo, and L.D. Samson, Balancing repair and tolerance of DNA damage caused by alkylating agents. Nat Rev Cancer, 2012. 12(2): p. 104-20.

3. Margison, G.P., M.F. Santibanez Koref, and A.C. Povey, Mechanisms of carcinogenicity/chemotherapy by O6-methylguanine. Mutagenesis, 2002. 17(6): p. 4837.

4. Saffhill, R., G.P. Margison, and P.J. O'Connor, Mechanisms of carcinogenesis induced by alkylating agents. Biochim Biophys Acta, 1985. 823(2): p. 111-45.

5. Klapacz, J., et al., Frameshift mutagenesis and microsatellite instability induced by human alkyladenine DNA glycosylase. Mol Cell, 2010. 37(6): p. 843-53.

6. Pfeifer, G.P., et al., Tobacco smoke carcinogens, DNA damage and p53 mutations in smoking-associated cancers. Oncogene, 2002. 21(48): p. 7435-51.

7. Richardson, F.C. and K.K. Richardson, Sequence-dependent formation of alkyl DNA adducts: a review of methods, results, and biological correlates. Mutat Res, 1990. 233(12): p. 127-38.

8. Head, R.J., et al., Persistence of DNA adducts, hypermutation and acquisition of cellular resistance to alkylating agents in glioblastoma. Cancer Biol Ther, 2017: p. 0.

9. McNerney, M.E., L.A. Godley, and M.M. Le Beau, Therapy-related myeloid neoplasms: when genetics and environment collide. Nat Rev Cancer, 2017. 17(9): p. 513-527.

10. Chaim, I.A., et al., In vivo measurements of interindividual differences in DNA glycosylases and APE1 activities. Proc Natl Acad Sci U S A, 2017.

11. Nagel, Z.D., I.A. Chaim, and L.D. Samson, Inter-individual variation in DNA repair capacity: a need for multi-pathway functional assays to promote translational DNA repair research. DNA Repair (Amst), 2014. 19: p. 199-213.

12. Chatterjee, N. and G.C. Walker, Mechanisms of DNA damage, repair, and mutagenesis. Environ Mol Mutagen, 2017. 58(5): p. 235-263.

13. Soll, J.M., R.W. Sobol, and N. Mosammaparast, Regulation of DNA Alkylation Damage Repair: Lessons and Therapeutic Opportunities. Trends Biochem Sci, 2017. 42(3): p. 206-218.

14. Kim, Y.J. and D.M. Wilson, 3rd, Overview of base excision repair biochemistry. Curr Mol Pharmacol, 2012. 5(1): p. 3-13.

15. Samson, L., et al., Cloning and characterization of a 3-methyladenine DNA glycosylase cDNA from human cells whose gene maps to chromosome 16. Proc Natl Acad Sci U S A, 1991. 88(20): p. 9127-31.

16. Samson, L.D., The repair of DNA alkylation damage by methyltransferases and glycosylases. Essays Biochem, 1992. 27: p. 69-78.

17. Li, M. and D.M. Wilson, 3rd, Human apurinic/apyrimidinic endonuclease 1. Antioxid Redox Signal, 2014. 20(4): p. 678-707.

18. Wilson, D.M., 3rd, M. Takeshita, and B. Demple, Abasic site binding by the human apurinic endonuclease, Ape, and determination of the DNA contact sites. Nucleic Acids Res, 1997. 25(5): p. 933-9.

19. Ko, H.L. and E.C. Ren, Functional Aspects of PARP1 in DNA Repair and Transcription. Biomolecules, 2012. 2(4): p. 524-48.

20. Wei, H. and X. Yu, Functions of PARylation in DNA Damage Repair Pathways. Genomics Proteomics Bioinformatics, 2016. 14(3): p. 131-139. 
640 21. Wilson, S.H., et al., DNA polymerase beta and mammalian base excision repair. Cold

641

642

643

644

645

646

647

648

649

650

651

652

653

654

655

656

657

658

659

660

661

662

663

664

665

666

667

668

669

670

671

672

673

674

675

676

677

678

679

680

681

682

683

684

685

686

687

688

689

690

Spring Harb Symp Quant Biol, 2000. 65: p. 143-55.

22. Tomkinson, A.E. and Z.B. Mackey, Structure and function of mammalian DNA ligases. Mutat Res, 1998. 407(1): p. 1-9.

23. Tomkinson, A.E. and A. Sallmyr, Structure and function of the DNA ligases encoded by the mammalian LIG3 gene. Gene, 2013. 531(2): p. 150-7.

24. Ensminger, M., et al., DNA breaks and chromosomal aberrations arise when replication meets base excision repair. J Cell Biol, 2014. 206(1): p. 29-43.

25. Calvo, J.A., et al., Aag DNA glycosylase promotes alkylation-induced tissue damage mediated by Parp1. PLoS Genet, 2013. 9(4): p. e1003413.

26. Ebrahimkhani, M.R., et al., Aag-initiated base excision repair promotes ischemia reperfusion injury in liver, brain, and kidney. Proc Natl Acad Sci U S A, 2014. 111(45): p. E4878-86.

27. Meira, L.B., et al., Aag-initiated base excision repair drives alkylation-induced retinal degeneration in mice. Proc Natl Acad Sci U S A, 2009. 106(3): p. 888-93.

28. Redaelli, A., et al., AP endonuclease activity in humans: development of a simple assay and analysis of ten normal individuals. Teratog Carcinog Mutagen, 1998. 18(1): p. 17-26.

29. Brenerman, B.M., J.L. Illuzzi, and D.M. Wilson, 3rd, Base excision repair capacity in informing healthspan. Carcinogenesis, 2014. 35(12): p. 2643-52.

30. Memisoglu, A.S., L., Base excision repair in yeast and mammals. Mutation Research, 2000. 451: p. 39-51.

31. Wallace, S.S., Base excision repair: a critical player in many games. DNA Repair (Amst), 2014. 19: p. 14-26.

32. Wallace, S.S., D.L. Murphy, and J.B. Sweasy, Base excision repair and cancer. Cancer Lett, 2012. 327(1-2): p. 73-89.

33. Abbotts, R., N. Thompson, and S. Madhusudan, DNA repair in cancer: emerging targets for personalized therapy. Cancer Manag Res, 2014. 6: p. 77-92.

34. Montaldi, A.P., P.R. Godoy, and E.T. Sakamoto-Hojo, APE1/REF-1 down-regulation enhances the cytotoxic effects of temozolomide in a resistant glioblastoma cell line. Mutat Res Genet Toxicol Environ Mutagen, 2015. 793: p. 19-29.

35. Montaldi, A.P. and E.T. Sakamoto-Hojo, Methoxyamine sensitizes the resistant glioblastoma T98G cell line to the alkylating agent temozolomide. Clin Exp Med, 2013. 13(4): p. 279-88.

36. Sultana, R., et al., Synthetic lethal targeting of DNA double-strand break repair deficient cells by human apurinic/apyrimidinic endonuclease inhibitors. Int J Cancer, 2012. 131(10): p. 2433-44.

37. Liu, L., Y. Nakatsuru, and S.L. Gerson, Base excision repair as a therapeutic target in colon cancer. Clin Cancer Res, 2002. 8(9): p. 2985-91.

38. Guo, J. and R.J. Turesky, Emerging Technologies in Mass Spectrometry-Based DNA Adductomics. High Throughput, 2019. 8(2).

39. Haque, K., et al., Accurate and sensitive quantitation of N7-methyldeoxyguanosine-3'monophosphate by 32P-postlabeling and storage-phosphor imaging. Chem Res Toxicol, 1997. 10(6): p. 660-6.

40. Liu, S. and Y. Wang, Mass spectrometry for the assessment of the occurrence and biological consequences of DNA adducts. Chem Soc Rev, 2015. 44(21): p. 7829-54.

41. Thomas, B., et al., A novel method for detecting 7-methyl guanine reveals aberrant methylation levels in Huntington disease. Anal Biochem, 2013. 436(2): p. 112-20.

42. Fortini, P., et al., Analysis of DNA alkylation damage and repair in mammalian cells by the comet assay. Mutagenesis, 1996. 11(2): p. 169-75.

43. Hartmann, A., et al., Recommendations for conducting the in vivo alkaline Comet assay. 4th International Comet Assay Workshop. Mutagenesis, 2003. 18(1): p. 45-51. 
691

692

693

694

695

696

697

698

699

700

701

702

703

704

705

706

707

708

709

710

711

712

713

714

715

716

717

718

719

720

721

722

723

724

725

726

727

728

729

730

731

732

733

734

735

736

737

738

739

740
44. Alanazi, J.S. and J.J. Latimer, Host Cell Reactivation: Assay for Actively Transcribed DNA (Nucleotide Excision) Repair Using Luciferase Family Expression Vectors. Methods Mol Biol, 2020. 2102: p. 509-528.

45. Wang, L., et al., A modified host-cell reactivation assay to measure repair of alkylating DNA damage for assessing risk of lung adenocarcinoma. Carcinogenesis, 2007. 28(7): p. $1430-6$.

46. Li, M., T. Ko, and S. Li, High-resolution Digital Mapping of N-Methylpurines in Human Cells Reveals Modulation of Their Induction and Repair by Nearest-neighbor Nucleotides. J Biol Chem, 2015. 290(38): p. 23148-61.

47. Mao, P., et al., Genome-wide maps of alkylation damage, repair, and mutagenesis in yeast reveal mechanisms of mutational heterogeneity. Genome Res, 2017. 27(10): p. 1674-1684.

48. Sutherland, B.M., P.V. Bennett, and J.C. Sutherland, DNA damage quantitation by alkaline gel electrophoresis. Methods Mol Biol, 2006. 314: p. 251-73.

49. Czaja, W., et al., Proficient repair in chromatin remodeling defective ino80 mutants of Saccharomyces cerevisiae highlights replication defects as the main contributor to DNA damage sensitivity. DNA Repair (Amst), 2010. 9(9): p. 976-84.

50. Czaja, W., P. Mao, and M.J. Smerdon, Chromatin remodelling complex RSC promotes base excision repair in chromatin of Saccharomyces cerevisiae. DNA Repair (Amst), 2014. 16: p. 35-43.

51. Bespalov, V.A., et al., Improved method for measuring the ensemble average of strand breaks in genomic DNA. Environ Mol Mutagen, 2001. 38(2-3): p. 166-74.

52. Alseth, I., et al., Biochemical characterization and DNA repair pathway interactions of Mag1-mediated base excision repair in Schizosaccharomyces pombe. Nucleic Acids Res, 2005. 33(3): p. 1123-31.

53. Sambrook, J. and D.W. Russell, Alkaline agarose gel electrophoresis. CSH Protoc, 2006. 2006(1).

54. Veatch, W. and S. Okada, Radiation-induced breaks of DNA in cultured mammalian cells. Biophys J, 1969. 9(3): p. 330-46.

55. Basenko, E.Y., et al., The LSH/DDM1 Homolog MUS-30 Is Required for Genome Stability, but Not for DNA Methylation in Neurospora crassa. PLoS Genet, 2016. 12(1): p. e1005790.

56. Strober, W., Trypan Blue Exclusion Test of Cell Viability. Curr Protoc Immunol, 2015. 111: p. A3 B 1-A3 B 3.

57. Trivedi, R.N., et al., The role of base excision repair in the sensitivity and resistance to temozolomide-mediated cell death. Cancer Res, 2005. 65(14): p. 6394-400.

58. Dianov, G.L., Base excision repair targets for cancer therapy. Am J Cancer Res, 2011. 7(1): p. 845-851.

59. Dianov, G.L. and U. Hubscher, Mammalian base excision repair: the forgotten archangel. Nucleic Acids Res, 2013. 41(6): p. 3483-90.

60. Boiteux, S. and S. Jinks-Robertson, DNA repair mechanisms and the bypass of DNA damage in Saccharomyces cerevisiae. Genetics, 2013. 193(4): p. 1025-64.

61. Fortini, P., The base excision repair: mechanisms and its relevance for cancer susceptibility. Biochimie, 2003. 85(11): p. 1053-1071.

62. Lawley, P.D., et al., Repair of chemical carcinogen-induced damage in DNA of human lymphocytes and lymphoid cell lines--studies of the kinetics of removal of O6methylguanine and 3-methyladenine. Chem Biol Interact, 1986. 57(1): p. 107-21.

63. Scicchitano, D.A. and P.C. Hanawalt, Repair of N-methylpurines in specific DNA sequences in Chinese hamster ovary cells: absence of strand specificity in the dihydrofolate reductase gene. Proc Natl Acad Sci U S A, 1989. 86(9): p. 3050-4. 
64. Wang, W., A. Sitaram, and D.A. Scicchitano, 3-Methyladenine and 7-methylguanine exhibit no preferential removal from the transcribed strand of the dihydrofolate reductase gene in Chinese hamster ovary B11 cells. Biochemistry, 1995. 34(5): p. 1798-804.

65. Ye, N., G.P. Holmquist, and T.R. O'Connor, Heterogeneous repair of N-methylpurines at the nucleotide level in normal human cells. J Mol Biol, 1998. 284(2): p. 269-85.

66. Smith, S.A. and B.P. Engelward, In vivo repair of methylation damage in Aag 3methyladenine DNA glycosylase null mouse cells. Nucleic Acids Res, 2000. 28(17): p. 3294-300.

67. Elder, R.H., et al., Alkylpurine-DNA-N-glycosylase knockout mice show increased susceptibility to induction of mutations by methyl methanesulfonate. Mol Cell Biol, 1998. 18(10): p. 5828-37.

\section{Author Statement}

755 Conceptualization: Wioletta Czaja, Peng Mao, Michael Smerdon. Funding acquisition: Wioletta 756 Czaja, Michael Smerdon. Investigation: Wioletta Czaja, Yong Li, Peng Mao, Evelina Y. 757 Basenko. Validation: Wioletta Czaja, Yong Li. Methodology: Wioletta Czaja, Peng Mao, Michael 758 Smerdon. Project administration: Wioletta Czaja. Resources: Wioletta Czaja, Michael Smerdon, 759 Zachary Lewis. Supervision: Wioletta Czaja, Michael Smerdon, Zachary Lewis. Visualization: 760 Wioletta Czaja. Writing-Original Draft: Wioletta Czaja. Writing - review \& editing: Wioletta Czaja, 761 Michael Smerdon, Peng Mao.

\section{Additional Information}

\section{Competing Interests}

764 None

765 We know of no conflicts of interest associated with this manuscript, and there has been no 766 significant financial support for this work that could have influenced its outcome. 